\title{
Bacterial meningitis in Swaziland: an 18 month prospective study of its impact
}

\author{
Helen Ford, John Wright
}

\begin{abstract}
Study objective - To describe the epidemiology, clinical features, and outcome of bacterial meningitis in Swaziland.

Design - Prospective study of patients diagnosed as having meningitis of nonviral aetiology during an 18 month period from February 1991 to July 1992.

Setting - Four regional hospitals covering the population of the four districts in Swaziland.

Subjects - All patients with non-viral meningitis admitted to hospital within the study period.

Main results - Altogether 85 patients were reported to have bacterial meningitis: $48 \cdot 3 \%$ were aged under 1 year. Causative organisms were identified in $\mathbf{6 0 \%}$ of cases, and Streptococcus pneumoniae was found to be the commonest (49\% of cases). Overall, case fatality was $\mathbf{3 8} \cdot \mathbf{8 \%}$ for all age groups, and $62.5 \%(15$ of 25$)$ for adults. Neurological sequelae occurred in $22.4 \%$. Three of the adult cases were HIV seropositive. Seizures, but not duration of symptoms before admission, were associated with a poor prognosis. There was a significant rise in incidence related to a period of drought. Fifteen patients were reported with tuberculous meningitis, of whom five were known to be HIV seropositive; the case fatality was $\mathbf{7 3 \cdot 3} \%$.

Conclusions - The aetiology and age distribution of cases of meningitis differs greatly from that in developed countries. Rising HIV infection may have an important impact on the future incidence of meningitis. The high case mortality found should encourage efforts towards earlier diagnosis and treatment, and strengthens the need to develop appropriate vaccines.
\end{abstract}

( $\mathcal{F}$ Epidemiol Community Health 1994;48:276-280)

Good Shepherd
Hospital,
PO Box 2,
Siteki,
Swaziland,
Southern Africa
H Ford
J Wright

Correspondence to: Dr J Wright, Registrar in Public Health Medicine, North Yorkshire Health Authority, Sovereign House, Kettlestring Lane, Clifton Moor, York YO3 4XF 3 September 1993 Bacterial and tuberculous meningitis remain major causes of mortality and morbidity in the developing world despite the availability of effective antimicrobial treatment. However, it is difficult to obtain a true picture of the extent of the problem because of the lack of accurate statistics. ${ }^{1}$

Previous studies of meningitis have been retrospective and have included little clinical information, concentrating on mortality rather than morbidity. ${ }^{2}$ Laboratory based studies have also failed to deal with clinical outcome. ${ }^{3}$ There is little recent information about meningitis in Africa, particularly with regard to the occurrence of sequelae and factors affecting outcome.

There have been important developments in the diagnosis and management of meningitis, including the introduction of rapid diagnostic tests, ${ }^{4}$ early treatment with penicillin, ${ }^{5}$ and the role of adjunct steroid treatment. ${ }^{6}$ The introduction of the new Hib vaccine has further implications for the prevention of meningitis. Adequate information about the disease in developing countries is essential to assess the impact of these developments and to allow for effective public health measures to be implemented.

Our aim was to provide information on the pattern of non-viral meningitis in Swaziland and to identify those factors affecting outcome which were amenable to change. We describe an 18 month study of the epidemiology of bacterial and tuberculous meningitis in Swaziland. We were particularly interested in studying the clinical outcome of meningitis in terms of both fatality and the diversity of neurological sequelae.

\section{Patients and methods}

The population of Swaziland is 750000 and the country is divided geographically into four regions. Each region is served by one district hospital with inpatient facilities, supported by rural outpatient clinics. The authors were working at one of the hospitals. All four district hospitals were invited to participate in the surveillance system.

Each village has access to a rural health motivator (RHM) who has a basic health training and lives in the community. Most people live within walking distance of a health centre. These are run by nursing staff, and visited regularly by a doctor from the nearest hospital. Transport is available from each health centre to the local hospital, and as the country is small, distances are not a major problem. Although there are inevitable delays, severely ill patients should reach one of the hospitals. There were occasional unexplained deaths in the community which would be reported to the local hospital by the RHM or clinical nurse.

From February 1991 to July 1992, with the support of the Ministry of Health and the
medical superintendents from each hospital, a prospective national reporting system was established to survey bacterial and tuberculous meningitis in Swaziland. It was assumed that all patients with meningitis who survived long enough would be admitted to hospital, and therefore reported.

A case report form was designed to standardise data collection and was distributed to all the centres. Information was recorded on 
age, sex, residence, time of symptom onset, date of admission, and cerebrospinal fluid (CSF) findings. Further clinical information was requested about previous history, treatment before hospital admission (traditional or medical), conscious level on admission, the occurrence of seizures, and clinical outcome.

Lumbar puncture and immediate CSF analysis were carried out in all patients presenting with clinical features suggestive of meningitis. Bacterial culture facilities were available in three of the four centres. Inclusion criteria for cases of bacterial meningitis were as follows: (1) positive CSF culture; or (2) positive CSF Gram stain but negative or unavailable culture; or (3) a CSF profile showing $>1000$ leukocytes $/ \mathrm{mm}^{3}$ (with $>75 \%$ polymorphonuclear leukocytes) with a CSF glucose concentration of $<1.9 \mathrm{mmol} / \mathrm{l}$ and a CSF protein level of $>1 \mathrm{~g} / \mathrm{l}$. A Gram stain showing only Gram negative diplococci was classified as Neisseria meningitidis even if CSF cultures remained negative. The diagnosis of tuberculous meningitis (TBM) was based on a clinical history of subacute or chronic meningitis with (1) positive Ziehl-Neelson stain or (2) CSF profile showing $100-400$ leukocytes $/ \mathrm{mm}^{3}$ (lymphocytic reaction), with a CSF glucose $<1.9 \mathrm{mmol} / \mathrm{l}$, and a CSF protein $>1 \mathrm{~g} / \mathrm{l}$. A presumptive diagnosis was supported by chest $x$ ray evidence of tuberculosis, skin testing, and sputum examination for acid-alcohol fast bacilli (AAFB). There were no facilities for culture of AAFB in the country.

Cases of viral meningitis or encephalitis and cases that did not fulfil the above criteria were excluded from the study. Indian ink staining was performed to examine for a fungal aetiology. HIV status was determined in those patients who fulfilled the clinical criteria for the WHO definition of AIDS, by initial ELISA and confirmation by western blot.

Antibiotic treatment was begun immediately after lumbar puncture. Standard treatment was initially with a combination of intravenous benzylpenicillin (adults $4 \mathrm{MU}$ four hourly; children $50000 \mathrm{U} / \mathrm{kg}$ four hourly) and chloramphenicol (adults $25 \mathrm{mg} / \mathrm{kg}$ six hourly;

Table 1 Fatality and neurological sequelae after bacterial meningitis related to age

\begin{tabular}{lccccrc}
\hline Age & \multicolumn{2}{c}{ Cases } & \multicolumn{3}{c}{ Fatality } & \multicolumn{3}{c}{ Sequelae } \\
& No & $(\%)$ & No & $(\%)$ & \multicolumn{1}{c}{ No } & $(\%)$ \\
\hline$<1$ mth & 6 & $(7 \cdot 1)$ & 3 & $(50 \cdot 0)$ & 1 & $(16 \cdot 7)$ \\
$1-11$ mth & 35 & $(41 \cdot 2)$ & 10 & $(28 \cdot 6)$ & 10 & $(28 \cdot 6)$ \\
$1-14 \mathrm{y}$ & 20 & $(23 \cdot 5)$ & 5 & $(25 \cdot 0)$ & 5 & $(25 \cdot 0)$ \\
Adult $(>15$ y) & 24 & $(28 \cdot 2)$ & 15 & $(62 \cdot 5)$ & 3 & $(12 \cdot 5)$ \\
\hline All cases & 85 & $(100.0)$ & 33 & $(38 \cdot 8)$ & 19 & $(22 \cdot 4)$ \\
\hline
\end{tabular}

Table 2 Type of bacterial meningitis with rates of fatality and neurological sequelae

\begin{tabular}{|c|c|c|c|c|c|c|}
\hline Age & $\begin{array}{l}\text { Cases } \\
\text { No }\end{array}$ & $(\%)$ & $\begin{array}{l}\text { Fatality } \\
\text { No }\end{array}$ & $(\%)$ & $\begin{array}{l}\text { Sequelae } \\
\text { No }\end{array}$ & $(\%)$ \\
\hline $\begin{array}{l}\text { Streptococcus pneumoniae } \\
\text { Neisseria meningitidis } \\
\text { Haemophilus influenzae } \\
\text { Others* } \\
\text { Unknown } \\
\text { All cases }\end{array}$ & $\begin{array}{r}25 \\
10 \\
8 \\
8 \\
34 \\
85\end{array}$ & $\begin{array}{r}(29.4) \\
(11.8) \\
(9 \cdot 4) \\
(9 \cdot 4) \\
(40.0) \\
(100 \cdot 0)\end{array}$ & $\begin{array}{r}12 \\
4 \\
2 \\
3 \\
12 \\
33\end{array}$ & $\begin{array}{l}(48 \cdot 0) \\
(40 \cdot 0) \\
(25 \cdot 0) \\
(23 \cdot 5) \\
(37 \cdot 3) \\
(38 \cdot 8)\end{array}$ & $\begin{array}{r}4 \\
2 \\
3 \\
2 \\
8 \\
19\end{array}$ & $\begin{array}{l}(16 \cdot 0) \\
(20 \cdot 0) \\
(37 \cdot 5) \\
(25 \cdot 0) \\
(23 \cdot 5) \\
(22 \cdot 4)\end{array}$ \\
\hline
\end{tabular}

* Others consisted of the following aetiologies: Escherichia coli (1), proteus (1), Staph aureus

(1), Gram negative bacilli (2), Gram positive cocci (3). children $12.5 \mathrm{mg} / \mathrm{kg}$ six hourly. After microbiological diagnosis, penicillin alone was continued in pneumococcal and meningococcal infections. Chloramphenicol alone was continued in Haemophilus influenzae infections. Standard treatment was continued in those cases with unknown bacterial aetiology. Treatment was continued for seven to 10 days.

In tuberculosis meningitis, quadruple antituberculosis treatment was used, with rifampicin, isoniazid, pyrazinamide, streptomycin daily for two months, then rifampicin and isoniazid only for a further 10 months.

Follow up of all cases was made six months after discharge at each regional centre.

Analysis of the results was carried out using the $\chi^{2}$ test and Fisher's exact test with Epi Info V5 software. Multiple regression was used to assess the significance of individual factors.

\section{Results}

During the 18 months period February 1991 to July 1992, 101 patients who fulfilled the study criteria of meningitis were admitted to hospital: 85 patients with bacterial meningitis $(84 \cdot 2 \%), 15$ patients with tuberculous meningitis $(14.9 \%)$, and one patient with cryptococcal meningitis. In the cases of bacterial meningitis, $44 \%$ were diagnosed on the basis of positive CSF culture, $16 \%$ on positive Gram stain alone, and $40 \%$ on CSF biochemistry.

The annual incidence, based on a national population figure of 750000 , was 13.5/100 000 .

For bacterial meningitis, children under 1 year formed the largest group, accounting for $48.3 \%$ of cases. Table 1 shows the number of cases, mortality, and complication rates in relation to the age of the patient. Nineteen patients ( $36.5 \%$ of survivors) had neurological sequelae at the time of discharge or at follow up (developmental delay $(n=6)$; hemiparesis $(n=2)$; ataxia $(n=3)$; seizure disorder $(n=2)$; cranial nerve palsy $(n=2)$; sensorineural deafness $(n=1)$; confusion $(n=2)$; and hydrocephalus $(n=1)$. Mortality was significantly higher in adults than in children $(62.5 \% v 29.5 \%$, $\left.p=0.005, \chi^{2}=7 \cdot 8\right)$. Only $25 \%$ of adult patients made a full recovery, compared with $44.3 \%$ of children.

There was a male:female ratio of $1 \cdot 8: 1$ (55.30), with no significant difference in outcome between the sexes.

The figure shows the monthly incidence of meningitis during the study period. There was a significant increase in incidence in the May to July quarter of 1992 compared with the same quarter of $1991\left(p=0.026, \chi^{2}=4.98\right)$, coinciding with a period of severe drought in the country.

Table 2 shows the outcome in relation to the organism detected. The causative organism was identified in $60 \%$ of cases, none of whom had received previous antibiotic treatment. Of the 34 patients in whom no organism was identified, six $(17 \cdot 7 \%)$ were known to have had antibiotic therapy before hospital admission. $S$ pneumoniae was the most common causative organism, accounting for $49 \%$ of identified cases, and was associated with the highest case 


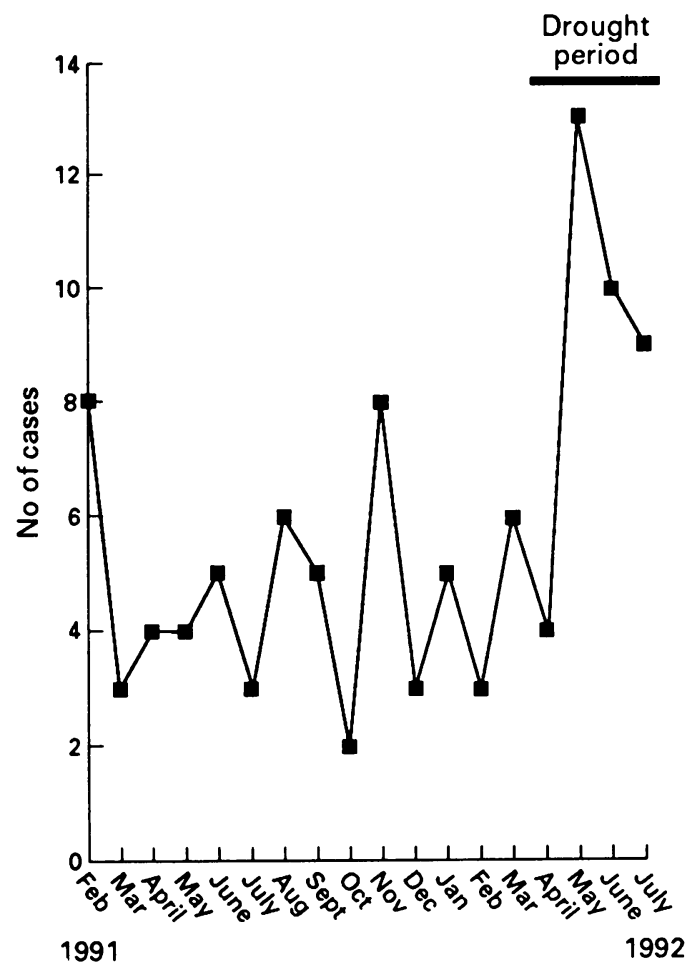

Monthly incidence of meningitis in Swaziland from February 1991 to fuly 1992.

mortality of $48 \%$. There was no significant difference in either the incidence of neurological sequelae $\left(p=0.79, \chi^{2}=1.73\right)$ or mortality $\left(p=0.79, \chi^{2}=1.72\right)$ in relation to aetiology.

Mortality and sequelae rates were studied in relation to the duration of symptoms before admission to hospital. There was no significant difference between the duration of symptoms and the final outcome.

Seizures before or during hospital admission were recorded in $16(18.8 \%)$ patients with bacterial meningitis. Eight of these patients died and only one made a full recovery. There was a significant association between seizures and both mortality and neurological sequelae $\left(p<0.005, \chi^{2}=8 \cdot 7\right)$. Seizures were more common in infants $\left(p<0.001, \chi^{2}=11.5\right)$.

Twelve patients were recorded as having been tested for HIV on clinical suspicion and nine (eight adults, one infant) were found to be positive: five had tuberculous meningitis, three bacterial meningitis ( $S$ pneumoniae in two cases and Staphylococcus aureus in the third) and one cryptococcal meningitis. Only three of these patients made a full recovery without sequelae.

Five patients were admitted in coma, of whom four died. Three patients had a previous

Table 3 Comparison of the aetiology of bacterial meningitis between Swaziland and England and Wales.

\begin{tabular}{lcc}
\hline Causative organism & $\begin{array}{l}\text { Swaziland } 1991 / 2 \\
(n=85) \\
\%\end{array}$ & $\begin{array}{l}\text { England E Wales } \\
1990(n=2219) \\
\%\end{array}$ \\
\hline Streptococcus pneumoniae & $29 \cdot 4$ & $7 \cdot 0$ \\
Neisseria meningitidis & $11 \cdot 8$ & $51 \cdot 3$ \\
Haemophilus influenzae & $9 \cdot 4$ & $19 \cdot 4$ \\
Others & $9 \cdot 4$ & $10 \cdot 2$ \\
Unknown & $40 \cdot 0$ & $12 \cdot 0$ \\
Total & $100 \cdot 0$ & $100 \cdot 0$ \\
\hline
\end{tabular}

history of head injury (two died), and 2 patients had predisposing or concurrent illnesses (chronic otitis media and pneumonia).

Fifteen cases of tuberculosis meningitis were reported, of whom nine were adults and two were infants. AAFB were not detected on $\mathrm{Z}-\mathrm{N}$ stain in any of the cases. The overall fatality was $73 \cdot 3 \%$ (11 of 15 ).

\section{Discussion}

This study was designed to provide active surveillance of meningitis in Swaziland. The incidence of all cases of meningitis was significantly higher than that reported in previous years (51 cases in 1988; 22 cases in 1989: Swaziland Ministry of Health data). National data were previously obtained through centralised voluntary reporting by clerical staff. It is likely that there was substantial under reporting of cases in these years.

\section{BACTERIAL MENINGITIS}

Children under 1 year formed the largest group. The age distribution found in our study is similar to that in other African populations and also to that in native American and aboriginal Australian populations. ${ }^{8}$ In contrast, in England and Wales children aged 1-14 years form the largest group with $41.7 \%$ (case fatality ratio $(\mathrm{CFR})=3.6 \%$ ) of reported cases and only $23.7 \%(C F R=3.6 \%)$ of cases occurred in children aged under 1 year. ${ }^{9}$ This marked difference in age distribution is important when considering the impact of vaccination programmes, as $\mathrm{Hib}$ and other vaccinations need to be more immunogenic to be effective in infancy. ${ }^{10}$ At present there are no immunisation programmes in Swaziland against $\mathrm{Hib}$, meningococcus, or pneumococcus.

An important finding of this study was the very high adult mortality, with only $25 \%$ of adult cases making a complete recovery. High CFRs for bacterial meningitis are often noted in the very young and the very old (usually $>60$ years, ${ }^{11}$ but most of our adult population was under 60 years old $(96 \%)$.

There was an increase in the incidence of bacterial meningitis in 1992 from May to July compared with the same quarter in 1991. This was a period of severe drought in Swaziland. ${ }^{12}$ This noticeable increase in incidence during the drought months may reflect a severe decline in nutritional status and in living conditions, resulting in overcrowding, during this period.

The most common organism isolated was $S$ pneumoniae $(49 \%)$, and this reflects the findings of other African countries. ${ }^{31314}$ In marked contrast, for England and Wales in 1990, 51\% of cases of bacterial meningitis were caused by $N$ meningitidis, with $S$ pneumoniae accounting for only $7 \%$ (table 3 ). ${ }^{15}$ In the United States, $H$ influenzae is the most common cause, with $S$ pneumoniae accounting for $18 \%$ of cases. ${ }^{10}$ Black Americans have been reported to have a higher incidence of pneumococcal meningitis than whites, even in the absence of sickle cell disease. ${ }^{1011}$ However, there is no evidence that 
race is an independent risk factor for particular causal organisms. The higher incidence is probably related to socioeconomic factors. ${ }^{16}$

In $40 \%$ of cases no organism was seen either on Gram stain or cultured from the CSF. This may be due to the widespread use of antibiotics in the community, although this was confirmed in only six out of 85 cases. A further contributory factor was the local diagnostic limitations. The poor yield of Gram stain and culture, particularly in cases with antibiotic treatment before hospital admission, has been documented. ${ }^{4}$ Of note, mortality in cases in whom no organism was identified, was not significantly different from that in the other cases, so the introduction of rapid diagnostic tests would not necessarily be cost effective.

Although there was a high overall CFR, similarly high rates have been found in other studies from developing countries $\left(33 \%^{2}\right.$; $\left.36 \%^{3} ; 44 \%^{17}\right)$. S pneumoniae accounted for the highest mortality and this pattern is consistent worldwide. ${ }^{18}$ Poor socioeconomic conditions and poor nutritional states undoubtedly contributed to the high mortality. The CFRs in our study may well be an underestimate of the mortality from meningitis, as patients with severe and rapidly progressing disease will die before reaching hospital and may go undetected.

Although there has been a significant fall in CFRs in the developed world, the rate of occurrence of neurological sequelae has remained constant. ${ }^{19}$ In our study, $22 \cdot 4 \%$ of patients had neurological sequelae at the time of hospital discharge. The incidence and range of neurological sequelae that we found was similar to that in other studies, although we might have expected to detect more patients with a hearing deficit. ${ }^{20}$ Clearly, it would have been useful if extended follow up had been possible.

Rehabilitation and support services are virtually non-existent in Swaziland, as in most developing countries, and the burden of handicap is therefore great. Although the early use of steroids may reduce the incidence of sequelae, ${ }^{6}$ prevention is likely to remain the most effective way forward.

Delay in starting antibiotic treatment has been associated with both increased mortality and morbidity. ${ }^{21}$ In view of our predominantly rural population and the difficulty of access to the regional hospitals, we felt it important to assess how much this delay affected outcome. There was no significant difference in either the CFR or neurological sequelae in relation to the duration of symptoms before hospital admission. Other outcome studies have found no association with mortality but a significant association with rates of sequelae. ${ }^{22}{ }^{23}$ However, the most striking association was found with duration of symptoms of less than eight hours before admission. Very few of our cases presented as early as this. It has been suggested that there is a spectrum of bacterial meningitis and that disease of insidious onset has a better outcome. ${ }^{24}$ Conclusions are difficult because of the unknown number of deaths before hospital admission.
Only $31 \cdot 3 \%(n=26)$ of patients presented to hospital within 48 hours of the onset of symptoms in our study. In two recent studies from developed countries, ${ }^{25}{ }^{26} 75 \cdot 5 \%(n=216)$ and $56.3 \%(n=462)$ of patients respectively presented within 48 hours - a significantly greater proportion $(p<0.001)$ of cases. This may be another determinant of the high mortality found in our study and other African studies. Traditional healers are an established part of society in Swaziland and provide the initial advice and treatment. This delay, and the problems of poor transportation and lack of public awareness, may explain the delay in presentation.

Three of the adult cases of bacterial meningitis were known to be HIV seropositive $(12.5 \%)$. The incidence of HIV seropositivity may have been significantly higher had all cases of meningitis been screened, rather than tested on the basis of a clinical suspicion of HIV infection alone. Bacterial infections of the central nervous system in patients with HIV infection have rarely been reported, ${ }^{27}$ and a recent study from Uganda found no association between HIV infection and meningococcal meningitis. ${ }^{28}$ In view of the rising incidence of HIV infection in southern Africa, further studies of bacterial meningitis should include routine screening for HIV infection to investigate the association more closely. It may be that HIV infection is an important adverse prognostic indicator and may partly account for the higher than expected adult mortality in this study.

\section{TUBERCULOUS MENINGITIS}

The difficulites of laboratory diagnosis of tuberculous meningitis are well described, such that empirical chemotherapy is justified for presumptive disease. ${ }^{29}$ It It should be stressed that the diagnosis was presumptive, based on clinical grounds and CSF findings. Even when culture facilities are available the diagnosis may remain unconfirmed bacteriologically and delay in treatment may be fatal..$^{30}$ In one case in which tuberculosis meningitis was suspected, Cryptococcus neoformans was identified.

The overall CFR of $73.3 \%$ in our study, despite quadruple antituberculous chemotherapy, is of great concern. It is noteworthy that five patients with tuberculous meningitis were HIV positive as was the patient with cryptococcal meningitis. A study of inpatients with tuberculosis in Swaziland showed an incidence of $29 \%$ HIV seropositivity. ${ }^{31}$ In those countries in which tuberculosis is endemic, tuberculosis meningitis may become an increasingly common complication of HIV infection.

\section{Conclusion}

In conclusion, our study has provided clinical and epidemiological information about meningitis in Swaziland, showing a different pattern of disease to that in developed countries. The high CFR is a cause of great concern and 
should prompt careful consideration of the prospects for its reduction. In view of the different age spectrum and aetiology of meningitis, $\mathrm{Hib}$ vaccination may not have the same impact in Swaziland as in the UK. However, a campaign to increase awareness among health workers about symptoms, early antibiotic therapy, and early referral has begun. The simple surveillance method used has greatly improved the accuracy of case detection and provided more comprehensive information about meningitis in the country. Future surveillance should monitor the impact of increased health awareness, as well as the impact of rising HIV infection.

We thank the doctors of the participating hospitals, in particular: Dr Aby Philip, Professor Richard Lacey for advice and material support, and Dr Jeffrie Strang for critical review. This research was supported by a grant from the National Meningitis Trust.

1 Greenwood BM. Selective primary health care: strategies for control of disease in the developing world. XIII. Acute bacterial meningitis. Rev Infect Dis 1984:6:374-89.

2 Bryan JP, de Silva HR, Tavares, A, Rocha H, Scheld WM Etiology and mortality of bacterial meningitis in northeastern Brazil. Rev Infect Dis 1990;12:128-35.

3 Guirguis N, Hafez K, Kholy MA, Robbins JB, Gotschlich EC. Bacterial meningitis in Egypt: analysis of CSF isolEC. Bactial Health Organ 1983;61(3):517-24.

4 Salih MA, Ahmed HS, Hofvander Y, Danielsson D, Olcen P. Rapid diagnosis of bacterial meningitis by an enzyme P. Rapid diagnosis of bacterial meningitis by an enzyme

5 Begg N. Reducing mortality from meningococcal disease. $B M \mathcal{A} 1991 ; 305: 133-4$.

6 Finch RG, Mandragos C. Corticosteroids in bacterial meningitis. $B M \mathcal{F} 1991 ; 302: 607-8$

7 Body R, Moxon ER. Immunisation of infants against Haemophilus influenzae type $\mathrm{b}$ in the UK. Arch Dis Child 1991;66:1251-4.

8 Wenger JD, Broome CV. Bacterial meningitis: epidemiology. In: Lambert, HP ed. Infections of the nervou system. London: Edward Arnold, 1991:16-31.

9 OPCS. Deaths by cause 1990. Mortality statistics, series DH2. London: Governmental Statistical Service 1991.

10 Schlech WF, Ward JI, Band JD, Hightower A, Fraser DW, Broome, CV. Bacterial meningitis in the United States, 1978-1981. F $A M A$ 1985;253:1749-54.
11 Wenger JD, Hightower AW, Facklam RR et al. Bacterial meningitis in the United States, 1986: a report of a multistate surveillance study. F Infect Dis 1990;162: 1316-23.

12 Wright J, Ford $\mathrm{H}$. Another African disaster. $B M \mathcal{F}$ 1992;305:1479-80.

13 Dube SD, Shenderov BA. Incidence and pattern of bacterial meningitis in Lusaka. Cent Afr 7 Med 1983;29:100-3.

14 Olanrewaja DM, Olusanya O, Laditan AA. Acute bacterial meningitis in children. West African fournal of Medicine 191;10:405-11.

15 OPCS. Notification of selected infectious diseases. London: Governmental Statistical Service, 1992. MB2 No 17

16 Fraser DW, Darby CP, Koehler RE. Risk factors in bacterial meningitis: Charlston County, South Carolina. $\mathcal{F}$ Infect Dis 1973;127:271.

17 Cados M, Denis F, Diop Mar I. Étude épidémiologique des cas de méningites purulentes hospitalisés à Daka pendant la décennie 1970-79. Bull World Health Organ 1981;59:575-84.

18 Noah ND. Epidemiology of bacterial meningitis: UK and USA. In: Williams JD, Burnie J, eds. Bacterial meningitis. London: Academic Press, 1987:93-115.

19 Smith AL. Neurological sequelae of meningitis. $N$ Engl $\mathcal{f}$ Med 1988;319:1012-13.

20 Salih MA, Khaleefa OH, Bushara $M$ et al. Long term sequelae of childhood acute bacterial meningitis in a developing country. A study from the Sudan. Scand $\mathcal{F}$ Infect Dis 1991;23:175-82.

21 Robinson RO, Roberts H. Acute bacterial meningitis: diagnosis. Dev Med Child Neurol 1990;32:79-86.

22 Bohr VA, Rasmussen N. Neurological sequelae and fatality as prognostic measures in 875 cases of bacterial meningitis. Dan Med Bull 1988;35:92-5.

23 Kilpi T, Antilla M, Kallio MJ, Peltola H. Severity of childhood bacterial meningitis and duration of illness before diagnosis. Lancet 1991;338:406-9.

24 Baird DR, Whittle HC, Greenwood BM. Mortality from pneumococcal meningitis. Lancet 1976;ii:1344-46.

25 Bohr VA, Rasmussen N. Neurological sequelae and fatality as prognostic measures in 875 cases of bacterial menas prognostic measures in 875 case

26 Kilpi T, Antilla M, Kallio MJ, Peltola H. Severity of childhood bacterial meningitis and duration of illness before diagnosis. Lancet 1991;338:406-9.

27 Levy RM, Bredesen DE, Rosenblum ML. Opportunistic central nervous system pathology in patients with AIDs. Ann Neurol 1988;23(suppl):S7-S12.

28 Kipp W, Kamugisha J, Rehle T. Meningococcal meningitis and HIV infection: results from a case control study in western Uganda. AIDS 1992;6:1557-8.

29 Kennedy DH, Fallon RJ. Tuberculous meningitis. $7 A M A$ 1979;241:264-8.

30 Traub M, Colchester AC, Kingsley DP, Swash M. Tuberculosis of the central nervous system. Quart $\mathcal{f}$ Med;209:81-100

31 Wright J, Ford $\mathrm{H}$. Tuberculosis and HIV infection. BMF right J, Ford H. 